\title{
Webcamming erótico comercial: nova face dos mercados do sexo nacionais
}

DOI

http://DX.DOI.ORG/10.11606/ 1678-9857.RA.2021.184482

\section{Lorena Rúbia Pereira Caminhas}

Universidade Estadual de Campinas / Campinas, SP, Brasil

lorenarubiapereira@gmail.com

ORCID: https://orcid.org/0000-0003-1009-3880

RESUMO

PALAVRAS-CHAVE

Este texto se debruça sobre o universo do webcamming erótico comercial (WEC) Webcamming, desenvolvido recentemente no Brasil (mais especificamente a partir do ano de 2002), investigando sua organização e estruturação (construindo um perfil dessa atividade em contexto nacional). Mantendo diálogo constante com a empiria e a literatura sobre o tema, este texto aponta para a urgência de empreendimentos que busquem singularizar essa atividade, constantemente subsumida a ramos mais conhecidos dos mercados do sexo, tais como a pornografia e o strip-tease. A estratégia metodológica adotada se baseou na etnografia, realizada primordialmente em ambiente online, sobretudo nos espaços dos sites especializados em WEC e redes sociais (especialmente o Twitter e o Instagram). Entrevistas semiestruturadas foram efetuadas com 15 camgirls (mulheres que atuam nesse ramo), centradas em suas trajetórias de vida e suas carreiras no webcamming.

Erotic commercial webcamming: new face of national sex markets

ABSTRACT This paper focuses on the erotic commercial webcamming (WEC) universe recently developed in Brazil (more specifically from 2002), investigating its organization and structuring (constructing a profile of this activity in a national context). Maintaining a constant dialogue with the empiricism and the literature on the issue, this text points to the urgency of enterprises that seek to singularize this activity, which is constantly subsumed to more popular branches of the sex markets, such as pornography and striptease. The methodological strategy adopted was ethnography in the online environment, especially in the spaces of specializing websites in WEC and social networks (especially Twitter and Instagram). In addition, we conducted semi-structured interviews with 15 camgirls (women who work in this field), focusing on their life trajectories and their careers in webcamming.

KEYWORDS

Webcamming, sex markets, eroticism, technologies 


\section{INTRODUÇÃO}

Fenômeno recente no Brasil, marcado por inovações tecnológicas e suas apropriações para fins libidinosos ${ }^{1}$, o webcamming erótico comercial (WEC) tem se expandido e se popularizado, configurando-se como um novo ramo dos mercados do sexo nacional. Surgido no início dos anos 2000 em solo brasileiro (precisamente a partir de 2002), ele é realizado predominantemente por mulheres que encenam diante da câmera atos eróticos e sexuais para uma audiência em troca de dinheiro e outros bens materiais. Essa atividade, a princípio dependente da iniciativa individual de garotas que anunciavam na rede suas apresentações, ganhou novos contornos a partir do aparecimento de sites especializados em exibição por webcam, vivenciando uma ampliação significativa do número de camgirls e de usuários². A década de 2010 é um importante marco a ser considerado, uma vez que nela houve a popularização e diversificação do WEC, com um aumento dos websites (atualmente são seis registrados no Brasil) e de pessoas envolvidas nesse universo (as modelos e seus espectadores, mas também o aparecimento dos "divulgadores"3), além da expansão de comunidades online de exibicionismo pago (sobretudo no Twitter), que proporcionaram maior visibilidade à prática e possibilitaram o convívio entre quem comercializa e consome o serviço.

OWEC é um desdobramento do homecamming, um estilo de transmissão online que predominou nos anos de 1990, constituído por um amplo contingente de mulheres (majoritariamente na faixa dos 13 aos 25 anos) que conectaram as recém-criadas webcams ao ambiente doméstico, compartilhando na internet suas experiências pessoais em tom confessional. As pessoas que difundiam sua imagem nesses moldes ficaram conhecidas como camgirls e seu principal objetivo, segundo Theresa Senft (2008), era conquistar um status de celebridade ao transmitirem para um amplo público suas vidas privadas. Quase simultaneamente ao nascimento do homecamming, modalidades de exibição eróticas e sexuais surgiram (tais como as "the porn cam" descritas por Senft (2008)), lançando mão da principal característica dessa prática: a interação mediada simultânea composta por um polo de exibicionismo e outro de voyeurismo. Nesse contexto, conforme nos revela Amy Dobson (2007), não tardou para que as camgirls fossem paulatinamente associadas às atrizes pornô, às strippers e às prostitutas, figurando como integrantes dos mercados do sexo.

Muitas das características do homecamming permaneceram no WEC contemporâneo, com destaque para a transmissão em tempo real; a predominância de mulheres jovens se mostrando na câmera; utilização do ambiente doméstico (especialmente o quarto) como locação para as imagens; encenações fundamentadas por um estilo confessional. Todavia, ocorreram muitas transformações a partir do momento em que o webcamming foi incorporado aos mercados do sexo, que afetaram tanto os modos de exibição quanto as formas de gestão e organização, a saber: as exibições passaram a ser exclusivamente eróticas e cobradas por minutos; a interação

1 Aponto como tecnologias fundamentais para o desenvolvimento do webcamming o computador pessoal, a internet, as webcams e o sistema de streaming (transmissão ao vivo). Ademais, indico como elemento central ao avanço dessa prática o processo de assimilação de diversos dispositivos tecnológicos no comércio sexual e erótico, fenômeno que denomino "midiatização dos mercados do sexo" (Caminhas, 2018).

$\mathbf{2}$ |As pessoas que se exibem na câmera são comumente conhecidas como camgirls ou camboys, modelos virtuais, webcam models e exibicionistas. Os indivíduos que consomem essas performances são chamados de usuários, público ou espectadores.

3 | Os divulgadores são perfis em redes sociais responsáveis por compartilhar fotos e vídeos das camgirls (também de garotas de programa e strippers), aumentando a visibilidade dessas mulheres. Eles promovem campanhas como "Musa do Twitter" ou "Gata da Semana", criando uma vitrine para as exibicionistas. 
com o público passou a acontecer por meio de distintas categorias de chats (simples, privado, exclusivo, dentre outros); e as apresentações (comumente conhecidos como shows) passaram a ser direcionadas pelos espectadores (ou usuários). Nesse sentido, o WEC é uma prática recente e singular, que não se confunde com outras modalidades de difusão audiovisual online em tempo real (tais como o próprio homecamming ou Snapchat e Twitcams), nem mesmo com outros ramos de comércio sexual e erótico aos quais ele é habitualmente associado (como o strip-tease e o pornô).

No presente artigo investigo o recente universo do WEC brasileiro, me concentrando em sua principal problemática: sua definição e delimitação enquanto prática comercial erótica que se aproxima a outros ramos dos mercados de sexo e erotismo, mas não se confunde a eles. De partida, esclareço que essa questão se estabelece em dois níveis distintos: o primeiro é o empírico, que envolve uma disputa por significados sobre o WEC, encenada predominantemente pelas camgirls que se esforçam para dissociar seu trabalho da prostituição; o segundo é o analítico, que compõem o atual campo de estudo sobre exibicionismo online no Brasil, campo esse responsável por disseminar uma profusão de nomenclaturas e classificações para a prática, associando-a à pornografia, ao strip-tease e à prostituição. Esses dois polos, ainda que distintos, alimentam uma mesma controvérsia sobre a especificidade do WEC, edificando tentativa e experimentalmente os sentidos atribuídos a essa atividade. Partindo de minha experiência etnográfica junto aos atores do webcamming, de minha interlocução com as modelos virtuais e também do conjunto da literatura nacional sobre o tema, busco destrinchar a configuração e a ordenação do WEC, compreendendo-o como um novo ramo de comércio sexual e erótico. Assevero que as características elencadas nas próximas páginas são próprias ao período atual de seu desenvolvimento e podem não coincidir com sua fase inicial.

\section{PERCURSOS METODOLÓGICOS}

A pesquisa que desenvolvo sobre o WEC brasileiro se iniciou em junho de 2016, amparada por etnografia e entrevistas semiestruturadas. A etapa etnográfica começou em ambiente online, investigando os sites especializados para exibição por webcam, buscando compreender seu funcionamento geral: a lógica de disposição das camgirls na homepage, a composição do perfil das modelos, o sistema de chat, os valores cobrados, as dinâmicas dos shows. Em seguida, me enveredei pelas redes sociais ${ }^{4}$, procurando aquelas que abrigavam o maior número de exibicionistas e espectadores. O Twitter é sem dúvida a mídia que mais agrega as pessoas envolvidas no WEC, seguido pelo Instagram. Nesses espaços, passei a acompanhar principalmente as mulheres, observando suas postagens e interagindo através de mensagens diretas, Whatsapp ou e-mails. Me concentrei também nas atividades dos websites, dos divulgadores e de

4 | Utilizei meu perfil pessoal em todas as redes sociais. Acredito que essa estratégia ajudou a me aproximar das camgirls, criando uma relação de confiança por elas terem acesso às informações pessoais de quem estava enviando as mensagens do outro lado do computador. alguns usuários mais proeminentes. Nesta fase, adotei como estratégia metodológica 
a mesma lógica que preside a utilização da internet cotidianamente, acessando os aplicativos do Twitter e do Instagram várias vezes ao dia, presenciando de perto a rotina das pessoas conectadas em minhas redes. Estive atenta às postagens, às enquetes $\mathrm{e}$ às discussões realizadas pelas camgirls na internet, percebendo seus horários, suas práticas diárias, suas opiniões sobre a exibição online e seus dilemas, todos divulgados via Twitter e Instagram ${ }^{5}$. Me encontrei pessoalmente com algumas camgirls na ocasião da Erotika Experience ${ }^{6}$, e tive a oportunidade de me apresentar e me familiarizar com suas apresentações. Desde que estabeleci o primeiro contato com as exibicionistas por meio de redes sociais, busquei manter minhas ideias e impressões sempre disponíveis às minhas interlocutoras, procurando revisá-las e atualizá-las.

Para elaborar as estratégias etnográficas segui majoritariamente a perspectiva de Hine $(2000,2015)$, considerando que a pesquisa de campo precisa ser multifacetada, abrigando os diversos espaços sociais nos quais as pessoas circulam e desenvolvem suas experiências, sejam eles online ou off-line (dispensando a diferenciação entre etnografia tradicional e virtual). Para essa autora, independentemente do ambiente social, a etnografia precisa dar conta do complexo arranjo entre os significados compartilhados, as ações dos sujeitos e as racionalizações sobre essas mesmas ações. Ao meu ver, os contornos e as consequências éticas do campo também precisam ser integrados em uma etnografia abrangente. Durante a pesquisa, tive poucas oportunidades de estar presencialmente com as modelos virtuais (principalmente devido às suas rotinas de apresentações), me concentrando em seus trânsitos no âmbito online. Ainda assim, tive acesso a muitas de suas práticas cotidianas fora da câmera durante nossas conversas, seja por mensagens diretas, seja por ocasião das entrevistas.

Passei a conhecer melhor as modelos virtuais quando iniciei a etapa de entrevistas semiestruturadas ${ }^{7}$, realizada com quinze mulheres entre junho e agosto de 2017. Me baseei na concepção de George Gaskell (2003), autor que considera a metodologia de entrevista essencial para compreender as concepções e os pontos de vistas dos atores sociais, deslindando seus modos de argumentação e racionalização. Essa estratégia investigativa tem a finalidade de "mapear o mundo da vida do respondente" (GASKELL, 2003, p. 65), detectando as tramas que perpassam a relação entre os atores e a composição das situações cotidianas, apreendendo os modos por meio dos quais o mundo social é construído ativamente pelos sujeitos e pelos sentidos que eles compartilham. O diálogo que estabeleci com as camgirls foi fundamental para que eu ampliasse minha compreensão das postagens que acompanhava através das redes sociais, entendendo sua importância dentro daquele universo (inclusive percebendo a relevância do próprio Twitter para criar um senso de comunidade no WEC).

Comecei a realizar as entrevistas enviando mensagens diretas no Twitter e no Instagram para as modelos que eu acompanhava, apresentando a mim e a pesquisa. Inicialmente obtive poucas respostas, muitas das quais recusavam o convite
5| Produzi um banco de print screen com as principais postagens, dividido em temáticas: enquetes e rifas; dados do perfil; discussões sobre o webcamming; ajuda; opinião sobre a postura dos usuários.

6| Estive na feira em og de junho de 2017. Fui com a intenção de conhecer algumas das modelos que eu havia entrevistado para tentar estabelecer uma conexão mais estendida e duradoura. Inicialmente consegui me aproximar de duas exibicionistas, que acabaram abandonando o webcamming pouco tempo depois.

$7 \mid$ Somente as mulheres exibicionistas foram entrevistadas. Os sites especializados e os usuários não demonstraram interesse em participar da pesquisa, nem mesmo respondendo a um questionário do tipo survey. Não expandi a pesquisa para camboys. Somente mais recentemente apareceram pessoas transexuais nesse ramo, as quais ainda não obtive acesso. 
para participar do estudo. Somente quando me aproximei da modelo que foi minha terceira interlocutora, Anelise ${ }^{8}$, que a investigação deslanchou e pude agendar vinte conversas (cinco delas não foram realizadas por decisão das camgirls). Anelise compartilhou em seu Twitter sua experiência na entrevista, afirmando que ela ajudaria a "esclarecer e divulgar o que são as camgirls". A partir desse momento, meu contato com o universo do webcamming se expandiu e passou a ser mais próximo e estendido, trocando mensagens e curtindo e compartilhando as postagens de minhas entrevistadas. Todos os diálogos aconteceram via conferência no Skype, respeitando a preferência de minhas colaboradoras. Todas as informações que pudessem identificá-las foram removidas, garantindo o sigilo tal como informado em Termo de Consentimento Livre e Esclarecido.

Somente após reunir o material concernente às entrevistas e às observações etnográficas consegui perceber mais claramente os contornos da controvérsia acerca definição e delimitação do webcamming e qual a sua importância, principalmente para as camgirls. Muitas de minhas interlocutoras enfatizaram a necessidade de divulgar informações sobre o exibicionismo online, demonstrando suas singularidades, afastando-o da prostituição. Inclusive, em todos os diálogos que estabeleci com as mulheres as características e idiossincrasias do WEC foram apontadas e reforçadas, externando um conjunto de sentidos que buscavam delinear essa atividade erótica. Tendo em vista a pungência dessa problemática na empiria, me dediquei a edificar um perfil tentativo e provisório para melhor demarcar e especificar o WEC. Essa foi uma etapa inicial, porém fundamental do estudo, que auxiliou na apreensão dos contornos do campo em análise e na compreensão dos mecanismos morais e éticos que perpassam a necessidade de distinção e diferenciação por parte das camgirls. Neste artigo me dedico a apresentar esse perfil, discutindo os principais traços do exibicionismo online. A título de contextualização, reconstruo brevemente a controvérsia ${ }^{9}$ que notei durante a etnografia e as entrevistas, e também na literatura nacional sobre o tópico.

\section{DISPUTAS POR SENTIDO E SENTIDOS DA DISPUTA NO WEBCAMMING BRASILEIRO}

Desde minha primeira incursão no território do webcamming nacional, prontamente observei uma pulsante controvérsia que circulava em meio às postagens das camgirls: uma necessidade pungente em afirmar que as modelos virtuais não eram prostitutas. Essa assertiva é facilmente identificada nas descrições dos perfis das modelos tanto em redes sociais quanto nos sites especializados, que advertem aos visitantes que as performances daquelas mulheres ocorrem "apenas no virtual". Não raro encontrei as seguintes postagens: "não faço real, apenas virtual" ou "não faço programa, apenas virtual". Nas narrativas das exibicionistas, a distinção entre real e virtual é a base
8 | Todos os nomes das entrevistadas são pseudônimos escolhidos aleatoriamente por mim a fim de manter sigilo de sua identidade.

9 | Reconheço a relevância de desvelar e compreender a controvérsia, percebendo suas causas e consequências para as práticas diárias das modelos virtuais (algo que desenvolvo em outros escritos). Inclusive, acredito ser de suma importância apresentar e discutir a busca por reconhecimento por trás das tentativas de separar webcamming e prostituição. Entretanto, considerando as demandas do campo em edificar um perfil para o WEC e o caráter inicial das pesquisas nacionais sobre o tema, considero fundamental a tarefa desenvolvida aqui, que colabora na compreensão do próprio fenômeno e suas dinâmicas singulares. 
para afirmar que o webcamming não se confunde ao programa, uma vez que nele não ocorreria sexo, mas apenas uma experiência erótica virtualizada (que aconteceria na imaginação). Em seus argumentos, o toque físico e a troca de fluídos própria ao sexo está ausente no exibicionismo online, que permite apenas diálogos picantes e simulação de práticas sexuais com vibradores, dildos e dedos. Durante as entrevistas, minhas interlocutoras enfatizaram constantemente que o principal aspecto de seus shows era a conversa, declarando que em boa parte de suas apresentações elas nem mesmo se despiam ou se levantavam da cadeira. Vale notar que a cada aspecto do WEC que minhas entrevistadas traziam à tona vinha acompanhado de uma contraposição à prostituição. Acompanhei em suas falas uma série de nomenclaturas que reforçavam esse contraste: em oposição às "garotas de programa" ou "acompanhantes" 10 (termos mais utilizados pelas camgirls para se referirem à pessoa que se prostitui), minhas colaboradoras se autodenominavam modelos virtuais, strippers virtuais, exibicionistas ou webcam models. Suas práticas são compreendidas como exibicionismo, strip-tease virtual ou shows por webcam (práticas essas consideradas distintas do programa). Nas entrevistas, muitas de minhas colaboradoras também ressaltaram a importância de reunir as principais características do WEC e divulgá-las para um amplo público, evitando uma possível "confusão" sobre essa atividade: como me disse Anelise, "muita gente vê errado, confundem modelos, que não passam de exibicionistas, com acompanhantes, porque quando você não tem informação a visão acaba sendo errada né".

Para as camgirls, singularizar o WEC é fundamental principalmente diante dos sites especializados e dos usuários, exatamente os dois atores desse universo que denominam as práticas por webcam de sexo. Nos websites, o webcamming é tratado como sexo virtual ou cibersexo. Inclusive em seus links e suas homepages, essas palavras aparecem em destaque, convidando ao público "para uma experiência sexual virtual única". Os usuários, por sua vez, buscam por sexo, muitas vezes com a expectativa de que as práticas desenvolvidas na tela possam ser realizadas pessoalmente. É muito comum, segundo as camgirls, que as pessoas em suas salas virtuais sempre questionem se elas "fazem real", continuamente tentando negociar programas fora da internet (em geral, oferecendo mais dinheiro). Aqui estamos diante dos elementos do campo contencioso do WEC nacional, subdividido em dois polos opostos: por um lado, o acionamento da ideia de sexo virtual pelos sites especializados vai ao encontro das expectativas dos usuários, aproximando o webcamming do programa; por outro lado, as noções de exibição e shows trazidas pelas modelos buscam distanciar o webcamming da prostituição, com o objetivo de individualizar e diferenciar as práticas realizadas online.

Certamente a disputa pela definição e delimitação do WEC que descrevo brevemente acima está relacionada a uma série de fatores ${ }^{11}$, dentre os quais se destaca o estigma da prostituição. Bem sabemos que no interior dos mercados de sexo e erotismo, muitos são os ramos que buscam se distanciar das prostitutas, a exemplo da
10| Estes dois termos acionados pelas camgirls hierarquizam e categorizam os diferentes tipos de programa, situando as "prostitutas" nos estratos mais baixo da prostituição enquanto considera as "garotas de programa" ou "acompanhantes" como a parcela menos precarizada das pessoas que comercializam sexo. Vale notar que mesmo diante dessa escala hierárquica, para as modelos virtuais toda venda de sexo acaba sendo considerado programa, sofrendo com as marcas do estigma.

11 Durante a pesquisa foram elencados e analisados uma série de elementos que dialogam com a necessidade de demarcação do webcamming por parte das camgirls, buscando compreender suas consequências. Ainda que essas questões sejam fundamentais para tencionar o perfil do WEC que apresento abaixo, na extensão deste artigo é impossível incluí-las. 
pornografia (DÍAZ-BENITEZ, 2009, 2013; ABBOTT, 2010), do disque-sexo (FLOWERS, 1998; SELMI, 2012), do strip-tease (FRANK e CARNES, 2010) e até mesmo outros arranjos de trocas comerciais sexuais (PISICTELLI, 2007). Como nos revela Agustín (2007), o termo prostituição funciona como uma construção linguística associada a um processo de categorização social, que constrói a "classe de mulheres perigosas", relacionada à criminalidade, à decadência moral e à pobreza. Temos de ter em mente que a controvérsia encenada predominantemente pelas camgirls objetiva uma singularização das práticas realizadas via webcam, que impacta diretamente nos processos de autoapresentação e autorrepresentação: nas narrativas das modelos dizer que o webcamming é "apenas virtual" (em oposição ao programa) possibilita afirmar que exibicionista não é "garota de programa".

Se em meu campo de pesquisa presenciei continuamente a disputa em torno da singularização do WEC, no escopo da escassa literatura nacional sobre a prática me deparei com uma profusão de nomenclaturas e caracterizações, que ora tratavam o webcamming como pornografia, ora como strip-tease, ora como prostituição. Em sua maioria, os artigos publicados classificaram o WEC como um efeito da internet sobre o pornô, que teria passado a ser interativo. As ideias de "pornografia amadora em tempo real" ou "pornografia online protagonizada por pessoas comuns" sem uso de roteiro e direção se destacou nos trabalhos de José Ribeiro e Thaís Miranda (2012), Maycon Lopes (2013) e Thaís Miranda (2014). Em Weslei Silva (2014), encontramos a noção de "strip-tease virtual". Já nos escritos de Maria Silva e Allyson Silva (2016) e Rafael Saldanha (2017), o exibicionismo online foi tratado como "práticas sexuais virtuais através de webcam", ou como "cibersexo pago", ou até mesmo como "ciberprostituição".

Quando se trata de especificar as características do WEC, encontrei apenas em Silva (2014) uma tentativa parcial de sistematização, enquanto que nos outros autores os principais aspectos dessa prática só eram comentados quando reconhecidos como inovações. Devido a todo o conjunto da literatura nacional se basear em outros serviços oferecidos nos mercados eróticos e sexuais para definirem o webcamming, o esforço de compreender as singularidades da atividade, bem como sua organização e estruturação, ficou relegado a segundo plano. A título de exemplo, em Ribeiro e Miranda (2012) e Lopes (2013) e Miranda (2014) as propriedades basilares do camming são a falta de script prévio para as performances na câmera e a encenação de sexo ao vivo - ambas derivadas da suposição de que o objeto sob escrutínio é uma "pornografia interativa". Já em Silva e Silva (2017), pesquisadores que trabalham mesclando prostituição e pornografia, o cerne das encenações em webcam é a exposição do sexual e do libidinoso, permitindo "muito mais do que o mero acesso ao conteúdo pornográfico disponibilizado, possibilitando para aqueles que acessam produzir seu próprio conteúdo" (p.150).

Seja pela facilidade de situar o webcamming em algum dos ramos mais populares da indústria do sexo, seja pela ausência de conhecimento mais vasto sobre o tema 
(causada pela inexistência de pesquisas extensivas e aprofundadas), o fato é que as nomeações e características apontadas pelos autores brasileiros não conseguem apreender o funcionamento e a organização do WEC nacional, nem mesmo evidenciar sua singularidade quanto uma nova modalidade de sexo/erotismo comercial. Somente Silva (2014) se dedicou a compreender a atividade, preservando algumas de suas singularidades. A produção subsequente desse autor - em textos como Silva e Jayme $(2015 a, 2015 b)$ e Silva $(2015,2016)$ - aponta uma série de traços importantes desse serviço e desvenda elementos fundamentais de sua dinâmica interna, tais como: funcionamento dos sites especializados, incluindo os valores praticados em cada chat; composição das encenações via webcam, abrangendo as práticas eróticas mais solicitadas; breve perfil das camgirls, levando em consideração idade, padrão físico e tempo de atuação; descrição resumida do processo de negociação das apresentações. Ademais, o pesquisador ainda revelou as proximidades e os distanciamentos desse ramo de outras modalidades de comércio de sexo e erotismo. Contudo, mesmo no estudo mais abrangente de Silva (sua tese de doutorado), ainda não há o esforço de decompor e detalhar a ordenação e estruturação do webcamming ${ }^{12}$, considerado como strip-tease online ao longo do trabalho-isto é, um desdobramento do strip-tease presencial possibilitado por inovações tecnológicas.

Tendo em vista os contornos do campo do WEC brasileiro, constituído pelas experiências dos atores sociais envolvidos nessa prática (camgirls, websites, usuários, divulgadores, etc.) e a partir das descrições e interpretações da literatura nacional, passo a deslindar nas próximas páginas um perfil tentativo e provisório do webcamming, buscando inventariar os principais eixos da atividade e suas características basilares. São abordados seis elementos principais, reconstruindo a dinâmica interna de cada um deles: a) plataformas para WEC; b) dinâmica dos shows; c) camgirls; d) interação com usuários; e) vantagens e desvantagens; f) importância das redes sociais.

\section{EM BUSCA DAS SINGULARIDADES DO WEBCAMMING NACIONAL}

Quando pensamos em mercados do sexo, nos deparamos com um conjunto heterogêneo de práticas sexuais e eróticas, serviços, bens de consumo, trocas comerciais, ramos de atuação, modos de interação (Agustín, 2007), que se diferenciam e se distinguem de modo processual no cotidiano, à medida que passam a fazer parte dos repertórios e das experiências. No geral, as fronteiras que separam os diversos tipos de trabalho sexual são frágeis e movediças, sempre sujeitas a alterações e revisões. OWEC, uma atividade recente em que os contornos ainda são imprecisos e nebulosos, não se distingue das demais modalidades de comércio de sexo e erotismo, que tentam constantemente se singularizar e se delimitar (Bernstein, 2007). Meu empenho em apresentar um perfil do webcamming, elencando suas principais características, procura assinalar os elementos que o marcam como um fenômeno novo e singular, que se aproxima de
12 | A bibliografia internacional é um pouco mais extensa que a nacional e nela encontramos esforços mais amplos de sumariar as principais características do camming, levando em consideração suas especificidades enquanto um novo ramo dos mercados eróticos, como podemos atestar nas pesquisas de Angela Jones $(2015,2016)$ e Paul Mathews (2017) e Dobson (2007), entre outros. 
outras atividades sexuais/eróticas, mas não se confunde a elas. Reconheço que esse é um empreendimento tentativo e inacabado, sujeito tanto às instabilidades e contradições do próprio WEC, quanto às atualizações e reavaliações de outros pesquisadores.

\section{PLATAFORMAS PARA WEC}

O webcamming é realizado por meio de distintas plataformas, dentre as quais as mais utilizadas são os sites especializados e o Skype. Os websites são comumente vistos pelas camgirls como "redes sociais eróticas", tal como discute Danyelle Hamilton (2015), que descreve essas páginas como um misto de comunidades virtuais e empreendimentos eróticos/sexuais. Ao observar os sites, compreendemos porque eles se assemelham às mídias sociais: vemos na homepage as camgirls dispostas em fileiras de cinco, ordenadas a partir de sua disponibilidade (online, em chat, off-line); desse espaço é possível acessar o perfil das modelos, composto por uma foto ao lado esquerdo com nome, seguida de uma breve descrição pessoal da mulher e das práticas que ela realiza online; ao centro, vemos um feed de notícias, com as postagens das exibicionistas e os comentários dos usuários; há ainda uma seção para vídeos e fotos (pagos e gratuitos).

As interações pelos sites também se assemelham as das redes sociais, com diferença das cobranças monetárias: as camgirls comunicam com seu público por meio de chats específicos (simples, privado e exclusivo), que são abertos em uma aba adicional ao perfil. Angélica foi quem primeiro me explicou o funcionamento desses chats: o simples ocorre em grupo e todos podem enviar mensagens (custa 1,35 créditos/minuto); o privado abriga a modelo, o usuário e um voyeur (2,40 créditos/ minuto o show e 1,65 para voyeurismo); o exclusivo permite somente a mulher e um espectador (no valor de 2,55 créditos/minuto) ${ }^{13}$. Para manterem uma sala nos websites, as camgirls pagam uma taxa de manutenção que varia de 40 a 50\% dos valores arrecadados em apresentações. Seus ganhos podem ser retirados diariamente desde que possuam entre 50 a 100 créditos no mínimo.

Além de serem a infraestrutura, os sites são também espaços que garantem a visibilidade das camgirls. É consenso entre minhas entrevistadas que o surgimento dessas empresas facilitou o WEC, agregando em um só lugar modelos e usuários. Dandara ressoa a opinião de suas colegas quando afirma que "a vantagem do site é a divulgação, então você não tem essa preocupação de divulgar o trabalho igual no Skype". Ademais, os websites garantem proteção: as informações pessoais são ocultadas, sendo proibido informá-las nos chats sob risco de banimento; o rosto e a voz podem ser escondidos (muitas modelos usam máscara ou se filmam do pescoço para baixo; outras não ligam microfone e utilizam somente mensagem de texto); pode-se bloquear cidades ou regiões; as transações financeiras são analisadas antes de serem concluídas, sem envolver os dados privados. Certamente a segurança também é subjetiva, aparecendo na narrativa das exibicionistas como uma junção
13 Os valores apresentados correspondem ao principal site brasileiro de webcamming. As outras páginas especializadas apresentam uma variação pequena no valor cobrado Em geral as modalidades de chat são as mesmas, apenas em dois websites é possível realizar os "gold shows" que são exibições pré-programadas e se baseiam em arrecadação de um valor mínimo estabelecido pela própria camgirl. 
entre afastamento físico/corporal e anonimato. Muitas das entrevistadas afirmaram se sentirem mais seguras por estarem em ambiente virtual, em que sua identidade pode ser escondida ou até mesmo disfarçada por meio de personagens e uso de acessórios como máscaras. É propriamente a barreira da virtualidade, compreendida como proteção, que figura nas falas das modelos quando buscam se diferenciar das "garotas de programa".

Outra plataforma para WEC é o Skype. Sua dinâmica é bastante diferente dos websites: nele as modelos negociam previamente as práticas realizadas nos shows e recebem pagamento adiantado. Em minha observação de campo no Twitter presenciei recorrentes anúncios de apresentações por Skype, todos eles acompanhados de descontos, principalmente os mais longos. Os valores são pré-estipulados, mas podem ser alterados a depender da disposição do usuário em investir mais dinheiro. Conversando com as camgirls, percebi que o Skype é mais vantajoso financeiramente porque nele o valor integral dos shows são depositados direto à modelo. Ademais, elas podem incluir outras práticas banidas nos sites, tais como chuvas dourada e negra ${ }^{14}$, e aumentar o preço da exibição.

Todavia, os shows por Skype também são fonte de prejuízos: os pagamentos

$\mathbf{1 4}$ | A primeira se trata de um fetiche com urina e são realizados por meio de depósitos ou transferências na conta pessoal da modelo, a segunda com fezes. oportunizando fraudes; ademais, as mulheres ficam mais expostas por precisarem informar dados pessoais e bancários a usuários que elas só irão conhecer no momento da apresentação (que podem, inclusive, nem ligar sua câmera). Minhas entrevistadas Anelise, Manuela, Cibele e Beatriz não utilizam esse comunicador instantâneo exatamente por receio de terem suas vidas privadas reveladas; as outras onze interlocutoras utilizam-no apenas com uma clientela selecionada, considerada confiável. Nicole, camgirls que iniciou sua carreira no Skype, apontou mais dois problemas dessa plataforma (que não se manifestam nos sites): primeiro, não há mecanismos de mediação e moderação, nem mesmo de banimento e restrição; segundo, a divulgação dos shows é mais complexa porque cada mulher precisa fazer sua propaganda individualmente em redes sociais, atingindo apenas o público que circula por esses espaços. Outrossim, o contato direto das exibicionistas com seu público, sem a mediação dos websites, ocasiona um aumento nas demandas por programas, ampliando sua aproximação com as prostitutas. Por isso mesmo, grande parte de minhas colaboradoras só acionam o Skype quando têm certeza de que o espectador não irá questionar se ela "faz real", compreendendo, em sua visão, como funciona os shows online.

\section{AS CAMGIRLS}

Desde que comecei a pesquisa de campo sobre o WEC, constatei que a maior parte das pessoas que atuam nesse ramo são mulheres cisgênero. Seja nas homepages dos sites, seja nas redes sociais, as camgirls povoam esse universo, deixando um pequeno espaço 
para homens e pessoas transexuais ${ }^{15}$. Seus perfis são variadíssimo e multifacetados: camgirls cuja fonte principal de renda são os websites e outras que trabalham também em empregos formais; camgirls que se apresentam apenas em páginas especializadas e outras que se exibem em mais de uma plataforma; camgirls que atuam em outros ramos eróticos/sexuais (modelos alternativas na indústria pornográfica ou acompanhantes); camgirls com pouco tempo na atividade e outras com muita bagagem; camgirls com pretensões de permanência distintas no webcamming (algumas gostariam de construir uma carreira sólida, enquanto outras precisam do dinheiro para fazer um curso superior ou abrir um negócio próprio); camgirls que usam máscara ou escondem o rosto e outras que não se importam de revelar a face; camgirls que criam personagens e outras que exibem sua personalidade; camgirls de faixa etária variada (de 19 a 47 anos, com predominância das mais jovens); camgirls com distintos corpos e fisionomias (bem magras, gordas, mais velhas, com cabelos coloridos, tatuagens e piercings, etc.); camgirls negras, pardas, brancas e também de descendência asiática ${ }^{16}$.

Diante dessa realidade, é impossível delinear um único perfil para as modelos, mas apenas cotejar alguns elementos comuns que nos ajudam a compreender a conduta das mulheres envolvidas nessa atividade. Apesar da diversidade de trajetórias e motivações para entrar no WEC, todas as minhas entrevistadas compartilham a frustração com empregos formais, que em sua visão pagam baixos salários e exploram o contratado. Todas concordam igualmente que no webcamming é possível ganhar dinheiro suficiente para ter uma vida estável e confortável. Em suas visões, o exibicionismo é uma alternativa também de ascensão econômica, tal como apontam Ana Paula da Silva e Thaddeus Blanchette (2009). Angélica, Fernanda, Cibele, Gisele, Eliane e Jennifer abandonaram cargos no comércio para buscarem aumento na renda e horários flexíveis. Anelise, Beatriz, Nicole e Lúcia só tiveram ocupações intermitentes. Carolina e Dandara são graduadas, com empregos convencionais, mas têm com o WEC um faturamento extra. Manuela passou por uma demissão e encontrou na exibição e no programa uma saída financeira. Denise é a única que diz se exibir "apenas por prazer", já que em sua narrativa seu atual salário "paga as contas".

É comum no WEC que as modelos possuam rotinas de shows, levando em consideração seus objetivos financeiros. No geral, as camgirls se apresentam à noite (na faixa das 21 h até às 3 h). Mesmo as que não têm horários fixos selecionam um turno do dia que consideram ser mais movimentado para ficar online (o início da manhã e o almoço são vistos como promissores). Todas as minhas entrevistadas relataram reservar dias para férias e folgas. Igualmente, todas estabelecem metas financeiras (diárias, semanais ou mensais) a fim de garantir faturamento estável (à exceção de Denise).

O tempo de permanência, bem como as pretensões de continuar ou abandonar o webcamming são variáveis: 13 das modelos que entrevistei começaram suas carreiras há pouco tempo (cerca de dois anos no máximo). Somente Carolina e Milena se mantêm por um período prolongado, 60 e 42 meses respectivamente. Observei
15 | No WEC brasileiro as pessoas trans, que apareceram apenas recentemente nesse ramo, são denominadas ou transex ou transboys. A nomenclatura camgirl se restringe às mulheres cisgênero.

16 | Durante minhas incursões pelo campo não foi possível notar uma preferência por alguma raça ou qualquer processo de hierarquização baseado em raça. No contexto internacional, Jones (2015) aponta para uma desigualdade de posição das modelos negras nos sites. Em verdade, a diferença que mais se acentua no WEC brasileiro é a de gênero, na medida em que há uma distinção notável entre pessoas cisgênero e transgênero, principalmente quando se trata das mulheres. A desigualdade de tratamento fica clara já nas homepages dos sites, em que as mulheres trans ficavam alocadas na última aba, quase escondidas. Somente mais recentemente houve um aumento de sua participação no webcamming, tornando sua seção mais destacada. 
que a renovação das camgirls é constante, sendo que todos os dias algumas deixam a atividade e outras começam a se exibir. Muitas mulheres que acompanho no Twitter só entram ocasionalmente nos sites, quando objetivam ganhar dinheiro extra (são intermitentes). Éverdade também que muitas circulam por outros ramos dos mercados do sexo, sobretudo a pornografia, deixando paulatinamente o WEC. Esses trânsitos são inclusive intensos: sete de minhas entrevistadas estão no Suicide Girls ${ }^{17}$ e também trabalham para produtoras pornográficas. Inclusive acompanhei pelo Twitter camgirls que fazem filmes para a Brasileirinha e outras empresas nacionais; algumas têm produção independente e amadora, distribuídas em sites como Pornhub ${ }^{18}$. Porém, são poucas as modelos que trabalham como "garota de programa" ou "acompanhante": somente Manuela circula por esses ramos. Durante as entrevistas identifiquei três posturas principais em relação às intenções e ao planejamento de permanência no exibicionismo: a primeira é composta por aquelas mulheres que não têm a intenção de sair (principalmente a curto prazo); a segunda abriga as garotas que entraram com uma finalidade específica (juntar dinheiro, pagar a faculdade, cobrir gastos extras); a terceira agrega as modelos que não querem ficar por longo prazo.

No Brasil, as camgirls têm a possibilidade de decidir mostrar ou esconder o rosto. Em minha experiência no universo do WEC percebi proporção similar de mulheres nos dois grupos, talvez uma porcentagem sutilmente maior daquelas que acobertam a face. Dentre minhas interlocutoras, somente quatro usam máscaras e uma se fotografa do pescoço para baixo. Devemos compreender que existe uma dinâmica complexa nesse jogo entre revelar e encobrir: na verdade, o semblante permanece oculto apenas em fotos e vídeos, ou em chats simples e gratuitos, mas raramente nos shows privados, mesmo com voyeurs. Isso porque o espaço das apresentações é considerado pelas modelos como mais íntimo e seguro (já que seria proibida a filmagem), resguardando sua imagem pessoal. Como Angélica mesma me disse, "o que acontece no privado, fica no privado". Essa interpretação diferencial sobre os espaços públicos e privados da internet direciona as condutas e interações das mulheres, que sempre avaliam em que momento e lugar possuem mais ou menos segurança. Mais uma vez, estamos comentando processos de percepção subjetiva sobre salvaguarda. Como me disse Beatriz, "a máscara não esconde muita coisa", ela funciona mais como "uma dúvida na verdade, porque se, por exemplo, meu pai ver, meus amigos, eles vão saber que sou eu, só que eles não poderiam publicar uma foto minha de máscara e dizer que é fulana".

Uma outra estratégia muito comum para manter o sigilo também comentada por Silva (2014) é a criação de uma personagem para atuar como camgirl, separando aquilo que as modelos consideram ser seu verdadeiro self de sua persona pública. Em verdade, são poucas as modelos que optam por desempenhar um papel diante da câmera. Angélica foi uma das entrevistadas que centralizou sua personagem: "só a única coisa que eu peço é que seja a personagem o foco, eu vou responder como quem
17 | Site para fotos de nudez de mulheres consideradas "alternativas": muito tatuadas, com modificações corporais, obesas ou muito magras, com estilo de roqueiras, etc.

18| Agregador de vídeos pornográficos produzidos em todo o mundo. 
dá vida à personagem", porque "o ideal é manter a personagem como camgirl, como se ela fosse vinte e quatro horas aquela menina". Apenas ela, em meio às quinze interlocutoras, enfatizou a total dissociação da camgirl em relação à sua personalidade.

Para Carolina a personagem é importante porque "tem fetichistas que querem que você crie essa personagem", mas à exceção desses usuários "eu sou mais ou menos uma mistura de mim mesma com essa personagem, ela já está mais que viva dentro de mim". Na visão de Fernanda assumir uma persona precisa ser algo natural, por isso ela é uma mistura de sua personalidade com outras características que ela considera essenciais para o webcamming, como a sensualidade e o erotismo. Jennifer adotou uma personagem muito conhecida da ficção por quem ela sempre teve empatia e compartilhava alguns traços de personalidade: "eu me identifico com a personalidade da personagem que é mostrada, ela é cativante, ela é inteligente”. Eliane e Manuela tentaram criar uma personagem, tática que acabou não funcionando a longo prazo. Eliane me disse que percebeu rapidamente o fracasso dessa estratégia: "aí foi onde deu aquele estalo que eu pensei comigo mesma, tenho que ser eu mesma né, que aí eu vou conseguir passar o que eu quero". Manuela passou pela mesma experiência: "eu por exemplo tentei no começo criar uma personagem, eu não conseguia, na hora de falar, que me perguntavam alguma coisa, não correspondia ao que eu tinha planejado na minha mente de personagem, então ali morreu o personagem".

Ainda que as modelos compreendam a personagem como uma forma de se dissociarem do trabalho erótico/sexual que exercem, cinco de minhas entrevistadas nunca pensaram em adotar essa estratégia, algumas utilizando inclusive seu nome verdadeiro. Esse é o caso de Denise, Gisele, Anelise, Lúcia e Nicole. Denise me disse que em muitas ocasiões se sente mais personagem em seu dia-a-dia do que na câmera. Anelise percebeu que essa estratégia "não ia fluir, foi então que eu larguei mão e peguei um nome artístico meu mesmo e fui eu mesma". Lúcia utilizou um prenome com o qual ela se identificava e "sempre fui eu mesma". Gisele e Nicole nem mesmo mudaram seu nome de batismo.

\section{RELAÇÃO CAMGIRLS E USUÁRIOS ${ }^{19}$}

O WEC, na concepção de Paul Bleakley (2014), é uma atividade "fundamentalmente interativa", constituída principalmente pela interlocução entre camgirls e usuários. Sua grande novidade é o acesso do público às performers, direcionando suas práticas eróticas. Nesse sentido, a interatividade é um dos principais bens comercializados, na medida em que se paga tanto pela interação quanto pelo conteúdo sexual/erótico. 0 público do webcamming é bastante heterogêneo: como pude perceber, é o perfil da

19| Nesta seção vou tratar esse tema levando em consideração somente a opinião das modelos, únicos atores do camming brasileiro que acompanhei sistematicamente e produzi entrevistas. Reconheço que a visão dos usuários possa ser bastante diferente do exposto nas linhas subsequentes e que minha abordagem é unilateral (fruto de estratégias de pesquisa e limitações encontradas em campo). exibicionista que direciona quem irá compor sua clientela. Em geral, os espectadores são homens, com pouca presença de casais e escassez de mulheres. As pessoas que 
consomem esse serviço que circulam também no Twitter são apenas homens. Para as modelos com que conversei, a faixa etária dos usuários varia de 35 a 55 anos, sendo geralmente homens com renda fixa e bom poder aquisitivo (haja vista o custo dos shows privados e exclusivos). Há também uma parcela bem jovem, em média com 20 anos, que buscam por exibições rápidas.

O público majoritário das camgirls Denise, Manuela, Angélica, Carolina, Cibele, Gisele e Dandara são homens, em geral mais velhos (chegando até 60 anos), muitos dos quais são casados. Lúcia também atende pessoas do sexo masculino, mas com idade inferior, por volta dos 18 a 35 anos. Nenhuma delas costuma se apresentar para mulheres e casais. Em contraste, seis de minhas entrevistadas atendem mulheres, que correspondem a cerca de $30 \%$ de seus espectadores totais (no caso de Milena, Fernanda e Eliane). Beatriz considera que seu perfil agrega muitos cônjuges e namorados (extrapolando os 30\%), a mesma realidade vivenciada por Anelise e Nicole. As duas últimas mais Jennifer possuem um público bem específico e segmentado: duas delas chamam a atenção por suas diversas tatuagens e piercings e a outra adotou uma personagem famosa da ficção, atraindo os nerds (pessoas que gostam de quadrinhos e jogos de videogames).

Todas as minhas entrevistadas afirmam possuir um público fixo e cativo. Mas mesmo essa parcela não costuma ligar a webcam, acionando-a apenas quando querem mostrar o pênis e a ejaculação. Pelo que pude perceber, muitas das pessoas que procuram pelo WEC também querem manter o seu sigilo, interagindo erótica e sexualmente com uma mulher sem comprometer sua identidade. Me parece que estamos diante daquilo que Bernstein (2007) denomina de "autenticidade limitada", na medida em que os usuários esperam ter prazer sexual na interação, mas sem precisar transgredir os limites da intimidade. Mesmo aqueles usuários que perguntam se as modelos "fazem real" procuram se manter escondidos quando da interação por meio de webcam.

Durante as entrevistas as camgirls fizeram questão de enfatizar que desenvolvem relações harmoniosas com os usuários, baseadas em diálogo. A conversa foi considerada por elas como um elemento essencial dos shows, aumentando sua proximidade de seu público (certamente ampliando também a lucratividade, já que as pessoas ficarão conectadas mais tempo). Percebi que o limite entre uma interação mutuamente orientada para outra desrespeitosa é uma linha muito tênue. Os espectadores esperam ter seus desejos realizados, importunando e constrangendo as muIheres até mesmo fora dos chats nos sites (por mensagens diretas no Twitter). Mesmo que as camgirls estabeleçam em seus perfis as práticas que realizam, é muito comum que essas mesmas práticas sejam solicitadas e exigidas, sendo que em muitas ocasiões de discordância as exibições são encerradas abruptamente pelos espectadores. A insistência para que elas "façam real" também figura com um ponto de atrito nessa interlocução. Outra questão enfatizada por Beatriz e Anelise é que alguns homens 
ultrapassam os limites da relação comercial, esperando que as mulheres estabeleçam um vínculo mais íntimo, sem cobrar pelos shows. Ainda que todas essas situações sejam recorrentes no cotidiano do WEC, para minhas interlocutoras a barreira da mediação tecnológica permite que elas possam "chutar" ou "banir" aqueles que "passam dos limites", garantindo sua segurança. Nesse sentido, segundo as camgirls, a relação com os usuários raramente figura como um problema ou incomodo.

\section{DINÂMICAS DOS SHOWS}

Os shows são exibições por webcam que envolvem camgirls e usuários, nas quais as mulheres mostram o corpo vestido e despido, dançam, conversam, realizam práticas eróticas/sexuais. Cada modelo estipula sua própria lógica de apresentação, sempre se pautando pelos desejos dos espectadores. Segundo minhas entrevistadas, alguns querem somente conversar, enquanto outros desejam apenas uma masturbação rápida; há também os fetichistas que gostam principalmente de dominação, inversão e podolatria ${ }^{20}$. Tendo em vista a pluralidade de formatos de exibições, nessa seção vou trabalhar a partir de exemplos dos processos individuais de cada entrevistada, buscando evidenciar as diversas possibilidades.

Em geral, minhas interlocutoras preferem shows médios ou longos, por serem mais práticos e proporcionarem maiores ganhos financeiros. A praticidade está relacionada ao ritual de preparação da modelo: segundo Fernanda, elas precisam "se maquiar, cabelo impecável, unhas limpas, tudo bonitinho". As roupas e os brinquedos devem estar organizados e disponíveis, a iluminação e o ângulo da câmera necessitam estar ajustados. Todos esses procedimentos tomam tempo, e caso alguma exibição seja muito curta, as camgirls terão que se reorganizar novamente para atender outro usuário: como me relatou Denise, nos shows curtos "eu tenho que me vestir de novo, voltar para o chat grátis e ficar ali conversando", mas nos longos "às vezes já é a grana da semana".

O desenvolvimento dos shows depende da dinâmica adotada por cada camgirls. Anelise explicou que o processo de negociação das apresentações é muito similar para a maioria das modelos, o que muda são as exibições privadas: primeiro as mulheres se conectam aos chats grátis ou simples e interagem com os usuários online; quando um deles convida para o privado elas passam a negociar as práticas eróticas. Anelise realiza muitos fetiches, principalmente a inversão. Denise segue a lógica descrita por Anelise, sendo que suas únicas restrições são o "fisting ${ }^{21}$ e não coloco outras coisas que não sejam vibrador; não faço chuva dourada nem negra, não faço aquela ejaculação feminina". Angélica é mais restritiva e não permite chat grátis, porque segundo ela "o usuário tem que entender a lógica do que é o trabalho de camgirl". Ela se despe apenas em chat privado ou exclusivo, nunca no simples. Angélica costuma se masturbar e dançar em seus shows; os fetiches são realizados apenas mediante presentes (em forma de créditos).
20| A grosso modo, a dominação é quando uma das partes, nesse caso a mulher, assume posição hierárquica superior à do homem, dominando-o; a inversão ocorre quando os papéis reconhecidos socialmente como de homens e mulheres são invertidos, inclusive a parti do uso de indumentárias do outro gênero; a podolatria é o fetiche com pés. Vale notar que no caso do WEC esses fetiches são realizados predominantemente entre a modelo e um usuário homem (raríssimos foram os relatos de fetichistas mulheres)

21 Prática erótica que consiste em introduzir a mão ou o antebraço na vagina ou no ânus. 
Beatriz pré-estipula as práticas que ela se dispõe a realizar em cada chat: "no simples eu bato um papo, provoco, danço, não costumo tirar a roupa; já no privado pode ser strip, masturbação, oral no meu dildo, vaginal com dildo ou dedos, anal", mas os fetiches precisam ser combinados, "por exemplo, podolatria, chuva dourada, submissão $0^{22}$, isso aí é combinado e só faço mediante presente". Carolina e Cibele seguem a mesma lógica de Beatriz: em chats pagos elas fazem strip-tease e masturbação, mas os fetiches somente com créditos extras. Em suas apresentações elas usam brinquedos apenas com usuários cativos, com os demais espectadores usam somente as mãos.

Dandara, diferentemente das outras entrevistadas, se apresenta em dupla eventualmente. Quando está sozinha costuma fazer penetração vaginal e anal com dildos e vibradores, mas acompanhada o mais comum é o sexo oral (com ejaculação na boca). Nos sites especializados ela conduz seu show acompanhando os desejos dos usuários, mas por Skype todas as práticas são combinadas de antemão, como valores pré-estipulados. Eliane, por sua vez, também trabalha com exibições pré-agendadas, marcadas por meio de mensagens diretas. Sua especialidade é o sexo oral em brinquedos eróticos (principalmente "garganta profunda"23), o pole dance e a dupla penetração.

Nicole constróiseu perfil como "namoradinha e fetichista", com shows baseados em podolatria, smoking-fetishe $e^{24}$ e fetiches com "ninfeta". Ela prioriza apresentações de "normalmente meia hora, que é um tempo suficiente, dá para conversar, dá para se exibir". As outras cinco entrevistadas (Gisele, Milena, Jennifer, Lúcia e Manuela) são adeptas de exibições espontâneas e de tempo médio (cerca de 30 minutos). Em geral, elas fazem strip-tease, masturbação e usam sex toys para penetração ou oral. Somente algumas delas realizam fetiches: Milena faz dominação e inversão, Gisele atende podólatras e Manuela realiza inversão. Jennifer trabalha com penetração anal.

Para além das práticas eróticas, todas as minhas entrevistadas afirmaram que em seus shows a conversa é central. Existe uma narrativa de que as camgirls atuam como confidentes de seu público, exercendo um serviço erótico apenas eventualmente. As exibicionistas não negam o caráter sexual/erótico de seu trabalho, mas buscam minimizar o seu relevo. Outras categorias também concorrem para fundamentar essa visão do webcamming: as ideias de sensualidade e imaginação sempre são mencionadas, tidas como o cerne das apresentações via webcam. A junção dessas noções cria uma representação do exibicionismo online como uma atividade complexa, que envolve uma série de dimensões interativas mais significativas que apenas a sexualidade e o erotismo.

\section{VANTAGENS E DESVANTAGENS DO WEC}

Durante as entrevistas, as camgirls enfatizaram três vantagens principais do WEC: os ganhos financeiros, a segurança e a flexibilidade de horários e local de apresentação.
22 |É a outra face do fetiche de dominação, quando uma das partes da relação quer assumir posição submissa.

23 Ato de introduzir um artefato (sex toys, pênis, etc.) até o fundo da garganta.

$\mathbf{2 4}$ | Trata-se de um fetiche porfumantes. As modelos que realizam essa prática costumam fumar online e soltar a fumaça de diversas formas distintas (enfatizando bem a fumaça) enquanto sensualizam para o usuário. 
Também em minha circulação no Twitter notei que as modelos destacam a importância desses dois últimos elementos, considerados como as melhores características do webcamming. Denise e Carolina concordam que os valores recebidos nos shows são satisfatórios (principalmente à vista de empregos formais). Os presentes, sejam créditos extras ou bens materiais, compõem o quadro de arrecadação, tornando o WEC atrativo. Para as minhas outras 13 interlocutoras, os lucros são o principal fator para permanecer no exibicionismo. O exemplo de Angélica é ilustrativo: em sua primeira experiência online o show durou cerca de 40 minutos e ela conseguiu ganhar $\mathrm{R} \$ 100,00$ líquido; trabalhando seis horas diárias, ela afirma receber quase $\mathrm{R} \$ 500,00$ por dia. Ademais, conforme me disse Dandara, é a própria mulher que estipula suas metas monetárias, sendo possível adaptar a rotina de trabalho em função dos rendimentos. A narrativa sobre finanças vem acompanhada de um sentido de liberdade pessoal e financeira, na medida em que as modelos acreditam serem donas de suas rotinas e do próprio dinheiro, sem terem impedimentos para conquistar suas metas de estilo de vida. Os empregos formais se apresentam como um contraponto a esse discurso, figurando como entraves à independência econômica e individual.

O segundo pilar das vantagens apontado pelas entrevistadas foi a segurança, considerando que o WEC oferece riscos mínimos de agressão física e exposição da identidade. Fernanda acredita que as camgirls conseguem preservar sua privacidade porque não necessitam revelar seu nome, dados pessoais e nem mesmo o rosto. Como os sites especializados se responsabilizam por agregar os usuários, a modelo consegue manter seu anonimato e também garantir bons rendimentos. Denise aponta o sistema de recebimento como uma segurança adicional, que impede a divulgação de suas informações bancárias. As trocas econômicas ocorrem entre o usuário e o website, eximindo a mulher da responsabilidade de negociar e receber os valores. Por fim, a possibilidade de retirar e banir pessoas das salas permite que as exibicionistas tenham controle de seu espaço online, evitando homens mal-educados e violentos. Para as camgirls, esse benefício representa seu domínio das e sua prerrogativa sobre as interações estabelecidas online, principalmente por considerarem que suas ações na internet não extrapolam o ambiente virtual (não têm efeito no "real"). Mais uma vez, estamos diante da dicotomia virtualidade e realidade, em que o primeiro está parcialmente resguardado das consequências do segundo. Certamente, no que tange às transações financeiras, é também mais cômodo para as mulheres não precisarem negociar diretamente com o público, tendo, por um lado, a garantia do pagamento, e, por outro lado, o distanciamento daquilo que elas compreendem como programa.

A terceira vantagem apontada pelas camgirls é a ampla flexibilidade de rotina e local de trabalho. Cibele, Jennifer e Dandara consideram cômodo transmitir de suas residências e se sentem mais seguras por estarem em ambiente fechado, blindado pela barreira do virtual. Segundo as modelos, ninguém tem acesso à sua localização, a não ser que elas informem. Os horários e dias de trabalho são igualmente flexíveis, 
permitindo que as próprias modelos estabeleçam suas rotinas. Eliane e Gisele inclusive disseram que é possível preservar finais de semana e feriados, e também tirar férias quando quiserem. As quinze entrevistadas consideram que no webcamming éa exibicionista quem estabelece suas próprias diretrizes e dinâmicas. Anelise e Lúcia só se mantêm no exibicionismo por não precisarem obedecer "normas impostas", nem mesmo interagir com quem elas não tenham afinidade. A flexibilidade é um dos pilares do sentido de autodeterminação compartilhado no universo do WEC: as modelos relatam uma autonomia que começa na decisão da organização do trabalho (quando e onde irão trabalhar) e culminam na definição e formatação dos contatos que serão estabelecidos. Mais uma vez, é o terreno da virtualidade, compreendido pelas camgirls como um espaço mais seguro e adaptável que "a realidade", que possibilita a livre-escolha.

Apesar da extensa gama de vantagens apresentadas pelas modelos, o webcamming também possui desvantagens. Jones (2016) discorre sobre três perigos principais: a) o capping, que consiste em filmar a performance online e disponibilizar em sites pornográficos; b) o doxxing, baseado no recolhimento de informações pessoais da camgirl por meio da internet a fim de as distribuir on line; c) diversas formas de assédio e perseguição decorrentes de mensagens incessantes, ofensivas ou indesejadas. Poucas foram as camgirls que apontaram desvantagens da atividade, dentre elas Angélica reforçou o perigo de ter um de seus shows filmado e disponibilizado, o que poderia devassar sua intimidade. Para Carolina a flexibilidade é similarmente dúbia, na medida em que "se você ficar doente um dia, você vai perder um dia, se você ficar doente dois dias, você perdeu dois dias e depois você tem que correr atrás do seu prejuízo". Milena foi a última entrevistada que apontou mais uma desvantagem: o isolamento. Como no geral as mulheres transmitem de casa e de seus quartos, elas passam muito tempo fechadas em suas residências, acarretando uma diminuição das relações sociais. É interessante pensarmos que a pouca ênfase em possíveis desvantagens caminha de mãos dadas com a necessidade das modelos em construir uma imagem do próprio trabalho, que passa a interferir diretamente em sua autoimagem. Toda a busca por se dissociar das "garotas de programa" também passa por pensar as qualidades e os defeitos das próprias práticas, que precisam figurar como uma melhor opção em face do programa. claro que não podemos desconsiderar que para muitas mulheres o WEC é a saída mais vantajosa em termos de trabalho, fazendo com que seus defeitos fiquem em segundo plano. Entretanto, é de se estranhar que apenas muito raramente os aspectos negativos venham à tona e que eles nunca apareçam como tema de discussão no Twitter (espaço no qual as mulheres debatem todos as dinâmicas do WEC).

\section{O PAPEL DAS REDES SOCIAIS}

Tanto em cenário nacional quanto internacional, as camgirls utilizam amplamente redes sociais (sobretudo o Twitter $^{25}$ e o Instagram) para divulgação de seus shows e 
para ampliar a comunicação com a audiência. Horários e dias de apresentação, bem como fotografias e vídeos são postados diariamente junto às rifas e listas de desejos. As mídias sociais são também espaços para troca de informação e configuram uma rede de ajuda mútua impossível através dos websites.

Angélica me explicou que atualmente utiliza mais seu perfil de trabalho do que o pessoal: em suas palavras, "o retorno foi muito interessante e não tem como desassociar, uma vez que você trabalha com uma coisa tão ligada à rede social". Angélica costuma divulgar suas fotos e vídeos, responder recados e comentar sua rotina diária, bem como todas as demais camgirls que acompanhei pelo Twitter e Instagram. Para Beatriz, o Twitter confere destaque individual à modelo: nos sites, o perfil da modelo é apresentado no meio de muitas outras mulheres e só aparece nas primeiras opções quando se está online; no Twitter, ao contrário, é possível fazer a publicidade pessoal e angariar mais usuários. Já Anelise se mantém nessas mídias por perceber que a venda de fotos e vídeos rende muito mais que nos websites. Ainda que nos últimos anos eu tenha acompanhado um aumento substancial da comunidade do WEC sobretudo no Twitter, com grupos exclusivos para usuários e a ampliação do número de divulgadores, nem todas as exibicionistas gostam de compartilhar sua imagem nesse espaço online. Em geral, muitas mulheres acreditam que eles promovem superexposição e podem ser um perigo à segurança, favorecendo, inclusive, o aumento de assédio do público que passa a enviar incessantes mensagens diretas.

Outro ponto importante do Twitter é que ele permite a interação entre as modelos, atuando como um espaço de troca de informações e rede de apoio. $E$ isto não é exclusivo no WEC: como apontam Teela Sanders et all. (2018) e Marjorie Kibby e Brigid Costello (2001), as redes sociais têm funcionando como ambientes para a interlocução entre as trabalhadoras sexuais de vários ramos, colaborando para que elas estabeleçam uma rede de proteção. Para Jennifer o Twitter foi essencial para estabelecer diálogo com mulheres de outros sites, conhecendo as diferenças de dinâmicas de trabalho e os principais tipos de usuários que podem ser encontrados no webcamming. Lúcia, que foi vítima de fraude por um de seus espectadores no website, divulgou seu problema online e recebeu apoio de suas colegas, que inclusive iniciaram uma rifa para ajudá-la. Em suas palavras, "muitas modelos ficaram do meu lado, elas entenderam meu lado, não ficaram em favor do site, elas ficaram ao meu favor".

\section{CONSIDERAÇÕES FINAIS}

Delimitar, definir e singularizar uma prática social não é um esforço menor nem preliminar em termos de pesquisa; são esses processos que criam e constituem o campo em análise, apreendendo neles seus principais traços distintivos. Intitular, descrever e qualificar confere existência a determinado fenômeno, posicionando-o em um campo semântico e simbólico próprio. O perfil que apresentei do WEC, ainda 
que provisório e sujeito a constantes alterações, transborda o plano da mera descrição e avança em um processo de interpretação das narrativas e atuações dos sujeitos no interior dessa prática.

Por um lado, para compreender a constituição do webcamming enquanto um serviço erótico e os contornos da controvérsia que se instaura em seu interior, precisamos partir necessariamente de sua constituição e organização, desvendando como ela concorre para fundamentar as questões socioculturais que perpassam essa atividade dos mercados do sexo e erotismo. Por outro lado, a constante necessidade de minhas interlocutoras em classificar e delimitar não pode ser apenas apresentada ou mesmo somente questionada, tentando desvendar suas motivações e consequências. Se formos levar essa demanda a sério, teremos de nos esforçar para entender o que distingue, na visão dos atores sociais, suas práticas das de outros ramos contíguos. Porque para as camgirls a diferença de seu trabalho para os programas é quase uma obviedade? Quais são as especificidades do webcamming que criam essa desconexão imediata entre erotismo virtualizado e sexo? Será somente uma questão estratégica para as modelos se diferenciarem das "garotas de programa"? Não existe uma racionalização sobre essa diferenciação fundamentada pelos principais aspectos do WEC? Ainda que eu não possa responder a essas questões no espaço que me resta, saliento que sem me debruçar sobre as singularidades e idiossincrasias dessa atividade seria impossível até mesmo colocar essas indagações. Ao meu ver, é fundamental que compreendamos como o WEC se constitui como uma novidade no comércio sexual e erótico nacional, que mantém diálogo com outros ramos dos quais empresta muitas de suas características: se trata de pensar a ordenação e o arranjo dos comércios sexuais e eróticos brasileiros, sem perder a singularidade de cada uma de suas partes.

Lorena Rúbia Pereira Caminhas é doutora em Ciências Sociais pela Universidade Estadual de Campinas (Unicamp) e pesquisadora do Crupo de Estudos Interdisciplinares em Ciência e Tecnologia (GEICT/Unicamp). Seus trabalhos se concentram na interseção entre os estudos de Gênero e Sexualidade e as pesquisas em Comunicação e Mídia.

CONTRIBUIÇÃO DE AUTORIA: Não se aplica

FINANCIAMENTO: O presente trabalho foi realizado com apoio da Coordenação de Aperfeiçoamento de Pessoal de Nível Superior - Brasil (CAPES) - código de financiamento 001. 


\section{REFERENCIAS BIBLIOCRÁFICAS}

ACUSTÍN, Laura. 2007. Sex at the margins: migration, labour markets and the rescue industry. London, Zed Books.

BERNSTEIN, Elizabeth. 2007.

Temporarily yours: intimacy, authenticity and commerce of sex. Chicago, The University of Chicago Press.

BLEAKLEY, Paul. 2014. '500 tokens to go private': Camgirls, cybersex and feminist entrepreneurship. Sexuality \& Culture (New York, Online), n. 8(4): 892-910. https:// doi.org/10.1007/s12119-014-9228-3

CAMINHAS, Lorena. 2018. "A midiatização dos mercados do sexo e a configuração da experiência erótica mediada". Galáxia, (37): 162-174. https:// doi.org/10.1590/1982-2554132548

DA SILVA, Ana e BLANCHETTE, Thaddeus. 2005. 'Nossa senhora da Help': sexo, turismo e deslocamentos transnacionais em Copacabana". Cadernos Pagu, n. 25: 249-280. http://dx.doi.org/10.159o/ S0104-83332005000200010

DÍAZ-BENÍTEZ, Maria. 2009. Nas redes do sexo: bastidores e cenários do pornô brasileiro. Rio de Janeiro, tese de doutorado, Universidade Federal do Rio de Janeiro.

díAZ-BENÍTEZ, Maria. 2013. "El quehacer porno en la construcción de imágenes de espectacularidad". Memoria y sociedad (Bogotá, Online), n. 17(34): 92-109. Disponível em https:// revistas.javeriana.edu.co/index.php/ memoysociedad/article/view/8309

DOBSON, Amy. 2007. "Femininities as commodities: camgirl culture". In: HARRIS, Anita (org.). Next wave cultures: feminism, subcultures, activism. New York, Routledge, pp. 125-150.
HINE, Christine. 2000. Virtual ethnography. London, Sage.

HINE, Christine. 2015. Ethnography for the internet: embedded, embodied and everyday. London, Bloomsbury Publishing.

FLOWERS, Amy. 1998. The fantasy factory: an insider's view of the phone sex industry. Philadelphia, University of Pennsylvania Press.

FRANK, Katherine e CARNES, Michelle. 2010. "Gender and space in strip clubs". In WEITZER, Ronald (org.), Sex for sale: prostitution, pornography and sex industry. New York, Routledge, pp. 115-138.

GASKELL, Geoger. 2012. "Entrevistas individuais e grupais". In: BAUER, Martin e GASKELL, George (org.), Pesquisa qualitativa com texto, imagem e som: um manual prático. Rio de Janeiro, Vozes, pp. 64-89.

HAMILTON, Danyelle. 2015. "Sex work in cyberspace: geographies of desire in digital frontiers of the United States". Senior Capstone Projects (California, Online), n. 507: 1-79. Disponível em https://digitalwindow. vassar.edu/senior_capstone/507

JONES, Angela. 2015. "For black models scroll down: webcam modeling and the racialization of erotic labor". Sexuality $\delta$ Culture (New York, Online), n. 19(4): 1-24. http://dx.doi.org/10.1007/s12119-015-9323-0

JONES, Angela. 2016. "I get paid to have orgasms': adult webcam models' negotiations of pleasure and danger". Sings: Journal of Women in Culture and Society (Chicago, Online), n. 42(1): 227-256. Disponível em https://doi.org/10.1086/686758 KIBBY, Marjorie e COSTELLO, Brigid. 2001. "Between the image and the act: interactive sex entertainment on the internet". Sexualities 
(New York, Online), n. 4(3), 353-369. https:// doi.org/10.1177\%2F136346001004003005

LOPES, Maycon. 2013. "Pornografia amadora em tempo real: observações preliminares sobre o cam4". Anais do SIMSOCIAL: 1-14.

MATHEWS, Paul. 2017. "Cam Models, Sex Work and Job Immobility in the Philippines". Feminist Economics (Chicago, Online), n. 23(3): 1-25. https://doi.or g/10.1080/13545701.2017.1293835

MIRANDA, Thais. 2014. "Pornografia online amadora: como lidar? Desafios metodológicos da pesquisa diante de uma temática controversa". Anais do $3^{\circ} \mathrm{CIAIQ}$ : 307-312.

PISCITELLI, Adriana. 2007. "Shifting boundaries: sex and Money in the northeast of Brazil". Sexualities (New York, Online), n. 10(4): 489-500. https:// doi.org/10.1177\%2F1363460707080986

RIBEIRO, José e MIRANDA, Thais. 2012. "Sites de vídeos pornográficos amadores: encenação, midiatização e exibicionismo do anonimato". Anais do XXI Compós: 1-12.

SALDANHA, Rafael. 2017. Você só precisa clicar: sexo virtual e masculinidades refletidas pelas webcams. Florianópolis, tese de doutorado, Universidade Federal de Santa Catarina.

SANDERS, Teela et al. 2018. Internet sex work: beyond the gaze. United Kingdom, Palgrave McMillian.

SELMI, Giulia. 2012. "Dirty talk and gender cleanliness: an account of identity management practices in phone sex work". In: SIMPSON, Ruth et al.(org.). Dirty work: concepts and identity. England, Palgrave McMillian, pp. 113-125.
SENFT, Theresa. 2008. Camgirls: celebrity and community in the age of social network. New York, Peter Lang Publishing.

SILVA, Weslei. 2014. O sexo incorporado na web: cenas e práticas de mulheres strippers. Belo Horizonte, tese de doutorado, Pontifícia Universidade Católica de Minas Gerais.

SILVA, Weslei. 2015. "Corpos e erotismo: encenação de strip-tease na internet”. Anais da XI Reunión de Antropología del Mercosul: 1-21.

SILVA, Weslei. 2016. "Corpos e simulacros: encenação de strip-tease na internet". Astrolabio (Barcelona, Online), n. 16: 93-121. Disponível em https://revistas.unc.edu.ar/index.php/ astrolabio/article/view/14238/14709

SILVA, Weslei e JAYME, Juliana. 2015a. "Striptease virtual: representações e práticas ou 'isso' é sexo?". Contemporânea (Salvador, Online), n.13(2): 311-328. http://dx.doi.org/10.9771/18099386contemporanea.v13i2.13991

SILVA, Weslei e JAYME, Juliana. 2015b. "Close na web: incorporando femininos desejáveis". Mediações, n. 20(1): 194-216. http://dx.doi. org/10.5433/2176-6665.2015V2on1p194

SILVA, Maria e SILVA, Allyson. 2016. "Sexualidade e virtualização em Câmera Privê: sociabilidade, desejo e consumo através de webcam". Bagoas, n. 5: 153175. Disponívelem https://periodicos. ufrn.br/bagoas/article/view/9677

SILVA, Maria e SILVA, Allyson. 2017. "A virtualização da relação sexual em CAM4: o corpo enquanto objeto de desejo e de consume". Revista Ártemis, n. XXIV(1): 143-155. https://doi.org/10.22478/ ufpb.1807-8214.2017v24n1.34363 